\title{
Selection of Ovine Oocytes by Brilliant Cresyl Blue Staining
}

\author{
Liqin Wang, Jiapeng Lin, Juncheng Huang, Jing Wang, Yuncheng Zhao, and Tong Chen
}

Key Laboratory of Animal Biotechnology of Xinjiang and Key Laboratory of Grass Livestock Reproduction and Breed Biotechnology, Ministry of Agriculture, Animal Science Academy of Xinjiang Uygur Autonomous Region, Urumqi 830000, China

Correspondence should be addressed to Juncheng Huang, h_jc@sina.com

Received 24 January 2012; Revised 28 February 2012; Accepted 22 March 2012

Academic Editor: Brad Upham

Copyright () 2012 Liqin Wang et al. This is an open access article distributed under the Creative Commons Attribution License, which permits unrestricted use, distribution, and reproduction in any medium, provided the original work is properly cited.

Sheep oocytes derived from the ovaries collected from the slaughterhouse are often used for research on in vitro embryo production, animal cloning, transgenesis, embryonic stem cells, and other embryo biotechnology aspects. Improving the in vitro culture efficiency of oocytes can provide more materials for similar studies. Generally, determination of oocyte quality is mostly based on the layers of cumulus cells and cytoplasm or cytoplasm uniformity and colors. This requires considerable experience to better identify oocyte quality because of the intense subjectivity involved (Gordon (2003), Madison et al. (1992) and De Loos et al. (1992)). BCB staining is a function of glucose-6-phosphate dehydrogenase (G6PD) activity, an enzyme synthesized in developing oocytes, which decreases in activity with maturation. Therefore, unstained oocytes (BCB-) are high in G6PD activity, while the less mature oocytes stains are deep blue $(\mathrm{BCB}+)$ due to insuffcient $\mathrm{G} 6 \mathrm{PD}$ activity to decolorize the $\mathrm{BCB}$ dye.

\section{Introduction}

Sheep oocytes derived from the ovaries collected from the slaughterhouse are often used for research on in vitro embryo production, animal cloning, transgenesis, embryonic stem cells, and other embryo biotechnology aspects. Improving the in vitro culture efficiency of oocytes can provide more materials for similar studies. Generally, determination of oocyte quality is mostly based on the layers of cumulus cells and cytoplasm or cytoplasm uniformity and colors. This requires considerable experience to better identify oocyte quality because of the intense subjectivity involved [1-3].

Mangia and Epstein [4] and Knobil and Neill [5] found that glucose 6-phosphate dehydrogenase (G6PDH) shows activity during mice oocyte growth. With the growth of oocytes, significant changes in G6PDH occur. In addition, $\mathrm{BCB}$ stains the cytoplasm blue or colorless depending on G6PDH activity $[6,7]$. Research in pigs [7-9], goats [1012], cows [13-16], mice [17], and dogs [18] indicate that the percentage of $\mathrm{BCB}+$ oocytes reaching the blastocyst stage is significantly higher than $\mathrm{BCB}-$ oocytes. To our knowledge, there are no reports regarding the in vitro developmental competence of sheep oocytes selected using BCB staining.
With regard to the relationship between oocyte diameter and the ability of oocytes to develop in cows, Otoi et al. [19] found that although smaller diameter oocytes are able to undergo meiosis, they are not equipped with the developmental competence to reach the blastocyst stage. Only when the diameter of the oocyte reaches a certain threshold will its in vitro developmental competence become sufficient. In a study of the relationship among porcine oocyte quality, follicular size, and oocyte size, Kim found that oocytes with larger diameters achieve higher developmental competence after nuclear transfer [20]. Similarly, the same result was derived from studies on goats [21]. Hence, in this study, the diameter of the sheep oocytes was used to certify the oocytes selected using BCB.

In studies on mice, pig, cattle, and so forth [22-26], glutathione (GSH) affects cytoplasmic and nuclear maturation of oocyte, and regulates oogenesis, fertilization, and embryonic development. The GSH concentration in oocytes increases as ovulation approaches. In addition, oocytes at the MII stage have relatively higher GSH levels than those at the GV stage. After fertilization, GSH concentration declines significantly. Thus, the GSH content in oocytes reflects the maturity of the cytoplasm, and lower levels of GSH will 
TABLE 1: The sequence of primers for quantitative real-time PCR.

\begin{tabular}{lcc}
\hline Genes & Gene sequence $\left(5^{\prime}-3^{\prime}\right)$ & Fragment $(\mathrm{bp})$ \\
\hline Mater & Forward: GCTGGAGGCGTGTGGACTG; Reverse: GGTCTGTAGATTAGAGGTGGGATGC & 168 \\
Zarl & Forward: TGCCGAACATGCCAGAAG; Reverse: TCACAGGATAGGCGTTTGC & 168 \\
Gdf9 & Forward: CCCCAGGATTACAAGGAAG; Reverse: CTGGATGTAACTCGACGTCTCT & 198 \\
$18 s$ & Forward: GAGAAACGGCTACCACATC; Reverse: GCTATTGGAGCTGGAATTAC & 198 \\
\hline
\end{tabular}

reduce the developmental competence of oocytes during in vitro maturation.

Liao et al. [27], Tong et al. [28], and Paradis et al. [29] found that growth differentiation 9 (GDF9), mater, zar1, and other maternal genes present different expressions at different stages of development in oocytes and embryos. In the laboratory, we showed that the expressions of GDF9, mater, zarl, and other maternal genes in oocytes and embryos are the most significant at the GV stage. Oocytes in MII stage and 2-cell to 16-cell stage embryos present low expression of the genes [30]. Therefore, oocyte maturation can be measured through the expression of GDF9, mater, $z a r l$, and other genes.

In previous studies that used $\mathrm{BCB}$ for selecting oocytes, an in vitro culture channel was generally highlighted to verify its effectiveness. To our knowledge, this paper is the first report that verified the effectiveness of $\mathrm{BCB}$ for oocyte selection in sheep through measurement of oocyte diameter, GSH levels, and maternal gene expression.

\section{Materials and Methods}

2.1. Oocyte Collection. Sheep ovaries were obtained from a local abattoir and transported in sodium chloride solution containing $1000 \mathrm{IU} / \mathrm{mL}$ penicillin and $1000 \mathrm{IU} / \mathrm{mL}$ streptomycin at $30^{\circ} \mathrm{C}$. At the laboratory, the ovaries were washed three times in sodium chloride. The oocytes were aspirated from follicles with the diameter of $2-6 \mathrm{~mm}$ using a 20 -gauge needle attached to a $10 \mathrm{~mL}$ syringe containing $1 \mathrm{~mL}$ of aspiration medium [TCM-199(B-2520, Sigma) supplemented with $1 \mathrm{mg} / \mathrm{mL}$ polyvinyl alcohol (P-1763, Sigma) and $29 \mu \mathrm{g} / \mathrm{mL}$ heparin sodium salt(H-3393, Sigma)]. Only oocytes with complete cumulus layers and homogeneous cytoplasms were selected for use.

2.2. Brilliant Cresyl Blue Staining Test. Immediately after oocyte collection, they were washed three times in Dulbecco's PBS (GIBCO) modified with the addition of $0.5 \%(\mathrm{w} / \mathrm{v})$ BSA (mPBS). Then, the oocytes were exposed to BCB (B5388, Sigma) diluted in $\mathrm{mPBS}$ for $90 \mathrm{~min}$ at $38.6^{\circ} \mathrm{C}$ in a humidified atmosphere, washed twice, and classified into two groups, according to their cytoplasm coloration. Oocytes with or without blue cytoplasmic coloration were designated as $\mathrm{BCB}+$ and $\mathrm{BCB}-$, respectively. $\mathrm{COCs}$ of the control group were incubated directly after selection without exposure to BCB for 90 min.

2.3. In Vitro Maturation of Oocytes. After oocyte classification, the oocytes were washed three times in the maturation medium [TCM-199 supplemented with $10 \%$ FBS (v/v), $0.05 \mathrm{IU} / \mathrm{mL}$ FSH, $0.05 \mathrm{IU} / \mathrm{mL} \mathrm{LH}, 1 \mu \mathrm{g} / \mathrm{mL} 17 \beta-$ estradiol, $24.2 \mathrm{mg} / \mathrm{L}$ Sodium pyruvate, $0.1 \mathrm{mM}$ cysteamine, and $10 \mathrm{ng} / \mathrm{mL}$ EGF]. Oocytes were transferred in groups (20-30/drop) into $50 \mu \mathrm{L}$ droplets of maturation medium and incubated for $24 \mathrm{~h}$ at $38.6^{\circ} \mathrm{C}$ in a humidified $5 \% \mathrm{CO}_{2}$ atmosphere under mineral oil (M-3516, Sigma).

2.4. RNA Extraction and RT-PCR. Total RNA was isolated using an RNeasy Micro Kit (Qiagen, Europe) according to the manufacturer's instructions.

RT-PCR condition: to mix $1 \mu \mathrm{g}$ total RNA and $1 \mu \mathrm{L}$ random six polymer primer, RNase-free water is made up to $14.5 \mu \mathrm{L}$ at $70^{\circ} \mathrm{C}$ for $10 \mathrm{~min}$, and experiences ice bath for $10 \mathrm{~min}$. Upon the transient centrifugation, $0.5 \mu \mathrm{L}$ RNA Inhibiter, $5 \times$ buffer $2 \mu \mathrm{L}, 10 \mathrm{mmol} / \mathrm{L}$ dNTP $2 \mu \mathrm{L}$, and AMV $1 \mu \mathrm{L}$ (TaKaRa) are added in for $42^{\circ} \mathrm{C}$ for $40 \mathrm{~min}$.

2.5. Standard Curve. Mater, Zar1, and GDF9 genes are, respectively, connected with $18 \mathrm{~S}$ rRNA and pMD20-T carrier. The restricted enzyme EcoR V is applied to linearize the plasmids of each gene, and linearized plasmid of each gene is undertaking dilute concentration so as to make standard curve.

According to the gene sequence in GeneBank, Oligo 6.0 software is used to design quantitative primers of ovine Mater, Zar1, and GDF9 gene and the internal reference gene 18s-rRNA (Table 1).

2.6. Quantitative RT-PCR. Quantitative RT-PCR (Roche, 1.5 LightCycle) reaction condition: for $2 \mu \mathrm{L}$ standard plasmid and the sample cDNA, each $5 \mathrm{pM}$ upstream and downstream primers are used, also including $2 \times$ FastStart DNA Master SYBR Green I $10 \mu \mathrm{L}$ (QIAGEN), plus RNase-free water to $20 \mu \mathrm{L}$. Reaction conditions: $95^{\circ} \mathrm{C}$ predenaturation for $10 \mathrm{~min} ; 55$ cycles include $95^{\circ} \mathrm{C} 10 \mathrm{~s}, 60^{\circ} \mathrm{C} 20 \mathrm{~s}$, and $72^{\circ} \mathrm{C}$ $20 \mathrm{~s}$. From $40 \sim 99^{\circ} \mathrm{C}$, the temperature for the melting curve is increased by $2^{\circ} \mathrm{C}$ per second and fluorescence signals are collected. In order to reduce the errors, the quantitative RTPCR is repeated once again. The average value is applied in the analysis. All samples were operated in duplicate and the mean value of each duplicate was used for all further calculations.

2.7. In Vitro Fertilization of Oocytes. After maturation, the oocytes were exposed to $0.1 \%$ hyaluronidase $(\mathrm{H}-3506$, Sigma) to remove most of the cumulus cells. They were washed three times in the fertilization solution and then transferred at 20 to $30 /$ drop into $50 \mu \mathrm{L}$ fertilization droplets. 
TABLE 2: Effect of BCB concentration on the selection and nuclear maturation after IVM of sheep oocytes $(\text { replicates }=3)^{\mathrm{a}},(\mathrm{mean} \pm \mathrm{S} . \mathrm{D}, \%)$.

\begin{tabular}{lccc}
\hline BCB concentration $(\mu \mathrm{M})$ & $N$ & BCB,$n($ mean \pm S.D, $\%)$ & BCB + oocytes in MII, $n($ mean \pm S.D $\%)$ \\
\hline 26 & 342 & $228(66.15 \pm 11.89)$ & $197(86.16 \pm 3.23) \mathrm{Aa}$ \\
52 & 181 & $125(69.08 \pm 0.21)$ & $71(56.62 \pm 2.43) \mathrm{Bb}$ \\
Control & 126 & & $98(77.78 \pm 2.75) \mathrm{c}$ \\
\hline
\end{tabular}

${ }^{a}$ Values in the same column with different small letters have differed significantly $(P<0.05)$; values with different large letters have extremely significant differences $(P<0.01)$.

We evaluated the motility of sperm cells under an inverted microscope and separated the motile sperm fraction by swim-up. The frozen semen was thawed in the test tube in a $39^{\circ} \mathrm{C}$ water bath. Then, $50 \mu \mathrm{L}$ of the thawed semen was placed in two conical tubes under $0.5 \mathrm{~mL}$ fertilization medium (SOF [31] with $20 \%$ estrus sheep serum, $6 \mathrm{IU} / \mathrm{mL}$ heparin sodium, and $100 \mathrm{IU} / \mathrm{mL}$ gentamicin) and incubated for $20 \mathrm{~min}$ in a humidified $5 \% \mathrm{CO}_{2}$ atmosphere at $38.6^{\circ} \mathrm{C}$. After incubation, $250 \mu \mathrm{L}$ from the top of each tube was removed and pooled in a $1.5 \mathrm{~mL}$ centrifuge tube and centrifuged at $200 \times \mathrm{g}$ for $4 \mathrm{~min}$. Viable spermatozoa collected at the bottom of the tube were washed with $1 \mathrm{~mL}$ fertilization medium and centrifuged again. Then, the sperm concentration was adjusted to $6 \times 10^{6} \mathrm{sperm} / \mathrm{mL}$. Subsequently, $25 \mu \mathrm{L}$ of sperm suspension was added into each fertilization droplet to obtain a final concentration of $2 \times 10^{6} \mathrm{sperm} / \mathrm{mL}$. The dishes were incubated for $18 \mathrm{~h}$ at $38.6^{\circ} \mathrm{C}$ in a humidified $5 \% \mathrm{CO}_{2}$ atmosphere.

2.8. In Vitro Embryo Culture. After fertilization, the cumulus cells were removed from the presumptive zygotes using a fine pipette in culture medium (SOF [31] supplemented with $3 \mathrm{mg} / \mathrm{mL} \mathrm{BSA}$ ) and washed three times. Groups of 50 to 80 zygotes were transferred to 4 -well plates containing $500 \mu \mathrm{L}$ of culture medium at $38.6^{\circ} \mathrm{C}$ in a humidified atmosphere containing $5 \% \mathrm{CO}_{2}, 5 \% \mathrm{O}_{2}$, and $90 \% \mathrm{~N}_{2}$.

\subsection{Experimental Design}

2.9.1. Experiment 1: Effect of $B C B$ Concentration on Oocytes Selection and IVM. The objective was to determine the effect of varying concentrations of $\mathrm{BCB}$ on oocyte selection and embryonic development. Two concentrations (26 and $52 \mu \mathrm{M}$ $\mathrm{BCB}$ in $\mathrm{mPBS}$ ) were evaluated. The oocytes were exposed to the $\mathrm{BCB}$ for $90 \mathrm{~min}$ and then classified as $\mathrm{BCB}+$ or $\mathrm{BCB}-$. The percentages of the $\mathrm{BCB}-$ and $\mathrm{BCB}+$ selected oocytes were recorded for each group, and then exposed to maturation medium. Control oocytes were washed and placed in the maturation medium immediately. After maturation for $24 \mathrm{~h}$, the percentage of oocytes that reached the MII for each class was evaluated. The experiment was repeated three times. Based on the results of Experiment 1,26 $\mu \mathrm{M}$ BCB was used in the succeeding experiments.

2.9.2. Experiment 2: Effects of BCB Screening on In Vitro Culture Efficiency. After classification, both $\mathrm{BCB}+$ and $\mathrm{BCB}-$ oocytes were pooled and used for IVP of embryos; the maturation, cleavage, and blastocyst production rates were recorded. After the selection, the oocytes were maintained in the maturation medium for $24 \mathrm{~h}$. Some of the oocytes were removed randomly, blown in $0.1 \%(\mathrm{w} / \mathrm{v})$ hyaluronidase to remove all the cumulus cells. Oocytes with polar bodies were recorded as mature oocytes, some oocytes from the pool were in MI or GV stage, so they were without polar body. The rest of the oocytes underwent IVF-IVC, after fertilization for $48 \mathrm{~h}$. Cleavage rate (cleavage/oocyte) was recorded. Oocytes without cleavage were discarded. The day of fertilization was recorded as Day 0. At Day 7, the blastocyst efficiency (number of blastocysts/oocyte number) was recorded. The experiment was repeated three times.

2.9.3. Experiment 3: Oocyte Diameters Selected by BCB Test. The oocytes from the maturation efficiency in Experiment 2 were selected randomly for diameter measurement. NISElements, the image analysis software, and the NICON microscope camera system were used to measure the diameter of $\mathrm{BCB}+$ and $\mathrm{BCB}-$ oocytes, including the zona pellucida.

2.9.4. Experiment 4: GSH Content in Oocytes after $B C B$ Selection. $\mathrm{BCB}+$ and $\mathrm{BCB}-$ oocytes were blown into $0.1 \%$ $(\mathrm{w} / \mathrm{v})$ hyaluronidase (Sigma) to remove all cumulus cells. The samples were prepared using a GSH kit (China, Biyuntian) according to the manufacturer's instructions. The GSH content of the $\mathrm{BCB}+$ and $\mathrm{BCB}-$ oocytes was measured using a microplate reader.

2.9.5. Experiment 5: Variations in Gene Expressions of GDF9, Mater, and Zar1 in Oocytes after the BCB Test. The cumulus cells were removed from the IVM-oocytes. Real-time polymerase chain reaction probes were applied to test the gene expression of GDF9, mater, and zar1.

2.10. Statistical Analysis. The data from Experiment 1 were analyzed by one-way ANOVA. One-sample $t$-test was applied to the remaining experimental data. The software used was SPSS 11.0. At $P<0.05$, the difference between treatments was considered significant. At $P<0.01$, the difference was considered extremely significant. Data are expressed as mean \pm standard deviation.

\section{Results}

3.1. Experiment 1: Effect of BCB Concentration on Oocytes Selection and IVM. Table 2 shows the percentage of the selected oocytes and the rates of nuclear maturation obtained after exposure to 26 and $52 \mu \mathrm{M} \mathrm{BCB}$. The percentages of 
TABLE 3: Comparison of developmental efficiency of BCB selected oocytes after the in vitro fertilization (repeated 3 times)

\begin{tabular}{lcccc}
\hline Oocyte classification & $N$ & Oocytes in MII & Cleavage $^{\text {b }}$ & Blastocyst $^{\mathrm{b}}$ \\
\hline BCB + & 201 & $172(86.16 \pm 3.23) \mathrm{A}$ & $170(84.31 \pm 2.13) \mathrm{A}$ & $53(34.4 \pm 13.55) \mathrm{A}$ \\
$\mathrm{BCB}-$ & 91 & $46(50.94 \pm 1.63) \mathrm{B}$ & $43(36.19 \pm 3.67) \mathrm{B}$ & $3(6.73 \pm 6.85) \mathrm{B}$ \\
\hline
\end{tabular}

${ }^{a}$ Values in the same column with different large letters have extremely significant differences $(P<0.01)$

${ }^{b}$ Percentage calculated from total number of oocytes.

TABLE 4: Diameter of $\mathrm{BCB}+$ and $\mathrm{BCB}-$ oocytes selected by BCB test $(\text { replicates }=3)^{\mathrm{a}}$.

\begin{tabular}{lcc}
\hline $\begin{array}{l}\text { Oocyte } \\
\text { classification }\end{array}$ & $N$ & Diameter $(\mu \mathrm{m})$ \\
\hline BCB + & 44 & $163.37 \pm 4.50 \mathrm{a}$ \\
BCB - & 44 & $159.25 \pm 7.75 \mathrm{~b}$ \\
\hline
\end{tabular}

${ }^{a}$ Values in the same column with different small letters have differ significantly $(P<0.05)$.

TABLE 5: GSH content in BCB+ oocytes and BCB- oocytes (replicates $=3)^{\mathrm{a}}$.

\begin{tabular}{llc}
\hline Oocyte classification & $N$ & GSH Content $(\mathrm{pM})$ \\
\hline BCB + & 90 & $6.39 \pm 1.19 \mathrm{~A}$ \\
BCB - & 90 & $0.26 \pm 0.11 \mathrm{~B}$ \\
\hline
\end{tabular}

${ }^{a}$ Values in the same column with different large letters have extremely significant differences $(P<0.01)$.

$\mathrm{BCB}+$ oocytes obtained after staining with $26 \mu \mathrm{M}(66.15 \%)$ and $52 \mu \mathrm{M}$ BCB (69.08\%) showed no significant difference; however, the maturation rate of $26 \mu \mathrm{M} \mathrm{BCB}+$ oocytes $(86.16 \%)$ was significantly higher $(P<0.01)$ than those in the $52 \mu \mathrm{M}$ BCB $(56.62 \%)$, and higher $(P<0.05)$ than those in the control group (77.78\%).

3.2. Experiment 2: Effects of BCB Selecting on In Vitro Culture Efficiency. Table 3 shows the differences of BCB selected oocytes in terms of maturation rate, cleavage, or blastocyst production. The rate of maturation, cleavage, and blastocyst of BCB+ oocytes was $86.16 \%, 85.29 \%$, and $34.4 \%$, respectively, which are significantly higher than those of BCB - oocytes $(P<0.01)(50.94 \%, 36.19 \%$, and $6.73 \%$, resp.).

3.3. Experiment 3: Oocyte Diameters Selected by BCB Test. Table 4 shows the diameter of $\mathrm{BCB}+$ and $\mathrm{BCB}-$ oocytes. The mean diameter of $\mathrm{BCB}+$ oocytes was $163.37 \pm 4.50 \mu \mathrm{m}$ (mean \pm standard deviation), significantly greater $(P<0.05)$ than the diameter of BCB- oocytes $(159.25 \pm 7.75 \mu \mathrm{m})$.

3.4. Experiment 4: GSH Content in Oocytes after the BCB Selection Test. Table 5 shows the GSH content of oocytes after the BCB selection test. The GSH content in BCB+ oocytes $(6.39 \mathrm{pM})$ was extremely higher than that of $\mathrm{BCB}-$ oocytes $(0.26 \mathrm{pM})(P<0.01)$.

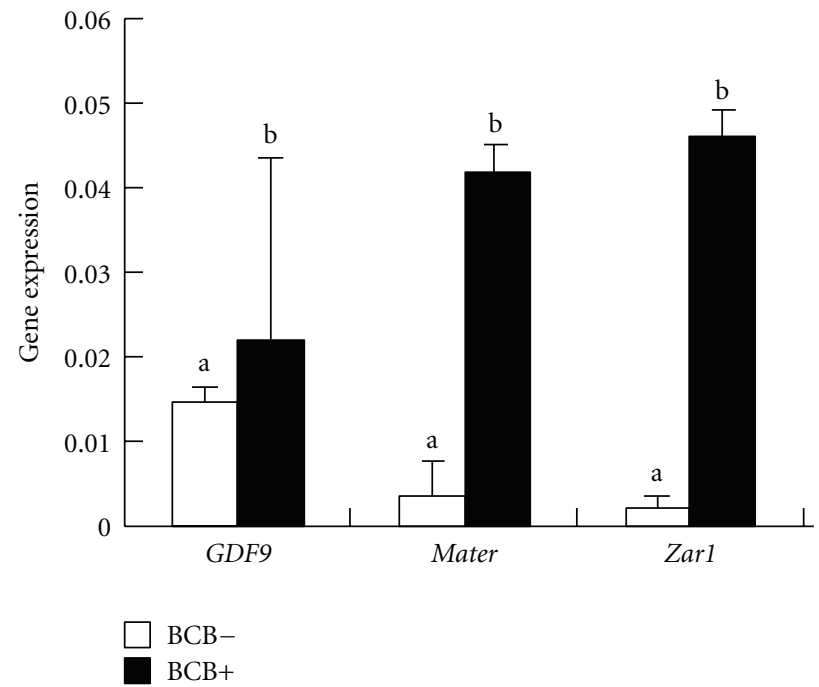

FIGURE 1: RNA expression of GDF9, mater, and zar1 in oocytes after $24 \mathrm{~h}$ maturation. The black column represents RNA expression of GDF9, mater, and zarl in BCB+ oocytes. The white Column represents RNA expression of GDF9, mater, and zar1 in BCBoocytes.

3.5. Experiment 5: Variations in Gene Expressions of GDF9, Mater, and Zar1 in Oocytes after the BCB Test. The expressions of the three maternal mRNA in BCB+ oocytes (GDF9, mater, and zar 1$)$ were significantly larger $(P<0.05)$ than in $\mathrm{BCB}-$ oocytes. The results are shown in Figure 1.

\section{Discussion}

In the study [7-17], immature oocytes stained by BCB. BCB+ oocytes showed higher rates of maturation, fertilization, and development to the blastocyst stage than BCB- oocytes. $\mathrm{BCB}$ can stain the cytoplasm and is an indicator of G6PDH activity. During the course of their growth, immature oocytes are known to synthesise a variety of proteins, including glucose-6-phosphate dehydrogenase (G6PDH). The activity of this protein is decreased once this phase has been completed and oocytes are then likely to have achieved developmental competence. In the growth and development of oocytes, G6PDH activity changes significantly with oocyte growth $[4,5,10]$. Thus, oocytes that have finished their growth phase show decreased G6PDH activity and exhibit cytoplasm with a blue colouration $(\mathrm{BCB}+)$, while growing 
oocytes are expected to have a high level of active G6PDH, which results in colourless cytoplasm (BCB-).

Previous reports using the $\mathrm{BCB}$ test in pigs found that $13 \mu \mathrm{M} \mathrm{BCB}$ can predict the maturation rate of oocytes better than $26 \mu \mathrm{M}[7,8]$. However, studies on the effects of $\mathrm{BCB}$ concentration on prepubertal goat [10-12], heifers [13], buffalo [16], and cattle [13-16] oocytes found that rate of maturation, cleavage, and development into blastocyst of oocytes selected using $26 \mu \mathrm{M}$ BCB were higher than in oocytes selected with $13 \mu \mathrm{M}, 39 \mu \mathrm{M}$, and $52 \mu \mathrm{M}$ BCB. Therefore, for the BCB selection of oocytes in different animals, the appropriate concentration of $\mathrm{BCB}$ needs to be determined. In terms of classification, sheep are closely related to goats and cattle. Thus, $26 \mu \mathrm{M}$ and $52 \mu \mathrm{M}$ BCB were selected for present study, which provided similar experimental results with prepubertal goat, heifers, buffalo, and cattle oocytes. The research has found that in the selection of sheep oocytes, $26 \mu \mathrm{M}$ and $52 \mu \mathrm{M}$ BCB achieved no significant difference in staining effect. In contrast, the rate of maturation of $26 \mu \mathrm{M} \mathrm{BCB}+$ oocytes $(86.16 \%)$ was extremely and significantly higher than $\mathrm{BCB}+$ selected by $52 \mu \mathrm{M}(56.62 \%)$ and higher than the control oocytes $(77.78 \%)$. The $26 \mu \mathrm{M}$ concentration allow us to obtain a high rate of selected oocytes. The percentage of $\mathrm{BCB}+$ oocytes (66.51\%) obtained in the present study, employing $26 \mathrm{mM}$ $\mathrm{BCB}$, seemed those similar to reported in heifer (62\% [32]; $66 \%[13])$, cow (58\% [14]) oocytes, but low than porcine oocytes (91\% [7], and $81 \%$ [8]). The percentage of BCB+ oocytes reported in oocytes recovered from 2-month-old goats and 3-6-month-old sheep were 30.1\% [33] and 19\% [34], respectively. They also reported that the $\mathrm{BCB}$ staining was influenced by oocyte morphology, thus differences in morphological selection criteria might be associated with the differences observed in percentage of BCB-stained oocytes among laboratories. This implies that $26 \mu \mathrm{M} \mathrm{BCB}$ was more suitable than $52 \mu \mathrm{M}$ concentration for selecting sheep oocytes. And we considered that $26 \mathrm{mM} \mathrm{BCB}$ could be used effectively in the study of embryo metabolism without being lethal as it was described by Tiffin et al. [35] in preattachment cattle embryos.

In the subsequent IVM, IVF, and IVC experiments, BCB+ oocytes had significantly higher cleavage and blastocyst rates (85.29\% and $34.4 \%$, resp.) than BCB- oocytes $(36.19 \%$ and $6.73 \%$, resp.). Thus, BCB staining can be used to greatly improve the in vitro culture efficiency of sheep oocytes. Elucidating the mechanism for the differences in oocyte quality as determined by $\mathrm{BCB}$ is the main purpose of our next experiment.

Oocyte diameter is a determinant factor to complete meiosis and acquiring full competence for embryo development [21], and it is closely related to oocyte developmental competence $[19,20,31]$. In our work we found that BCB test was helpful in selecting larger oocytes with $163.37 \pm 4.5 \mu \mathrm{m}$ diameter $(\mathrm{BCB}+)$ compared to those of $159.25 \pm 7.75 \mu \mathrm{m}$ $(\mathrm{BCB}-)$. This confirmed previous reports in cattle $(152.6 \mu \mathrm{m}$ versus $147 \mu \mathrm{m})$ [14], goat $(136.6 \mu \mathrm{m}$ versus $125.5 \mu \mathrm{m})$ [11], pigs $(113.08 \mu \mathrm{m}$ versus $100.29 \mu \mathrm{m})$ [9], heifer $(152.6 \mu \mathrm{m}$ versus $147.0 \mu \mathrm{m})$ [13], and prepubertal sheep $(123.66 \mu \mathrm{m}$ versus $106.82 \mu \mathrm{m}$ ) [34] for $\mathrm{BCB}+$ and $\mathrm{BCB}-$, respectively.
After IVM, we found a significant increase of $12 \mu \mathrm{m}$ of the internal zona diameter in $\mathrm{BCB}-$ oocytes, while $\mathrm{BCB}+$ oocytes maintained the same diameter after 24 hours of in vitro culture. Croet et al. [36] described the relationship of oocyte diameter to follicle size in adult goats, as well as to in vitro culture efficiency. When the follicle develops from $0.5 \mathrm{~mm}$ to $5 \mathrm{~mm}$, the oocyte diameter grows from $96 \mu \mathrm{m}$ to $146 \mu \mathrm{m}$, and the blastocyst efficiency of in vitro culture increases from $6 \%$ to $26 \%$. Kim et al. [20] obtained the same result in similar studies involving pigs. Damiani et al. [37] found that if the oocyte volume is relatively small, its competence for protein synthesis, energy metabolism, and migration of cytoplasmic organelles are decreased significantly. So this finding confirms that $\mathrm{BCB}+$ oocytes may have finished their growth phase when they are directly recovered from the ovary. This is the probable reason why oocytes of relatively small diameter have poorer viability.

Though the biochemical basis of $\mathrm{BCB}$ metabolism in oocyte is not fully understood, some evidence for the ability of BCB to play a role as electron acceptor and thereby become colourless during the electron flow induced by treated oocytes was then divided into BCB- (colorless cytoplasm, increased $\mathrm{G} 6 \mathrm{PDH}$ ) and $\mathrm{BCB}+$ (colored cytoplasm, low G6PDH) on their ability to metabolize the stain has been reported [14]. And we also observed that blastocyst development increased as the ovine oocyte diameter increased. Thus, the percentage of blastocysts was significantly higher in $\mathrm{BCB}+$ oocytes than $\mathrm{BCB}-$ oocytes.

Luberda [23] found that the maturation of oocyte cytoplasm involves a series of complex molecular reactions, including biological macromolecule synthesis, protein phosphorylation, and activation of certain metabolic pathways. The main function of GSH in oocytes is antioxidation, to prevent the oocyte from being poisoned by reactive oxygen species (ROS), while maintaining the meiotic spindle forms, and protecting the spindle from oxidative damages [38]. In addition, GSH concentration is very important for the maturation and fertilization of oocytes. In the maturation period of oocytes, GSH accumulation can improve the cytoplasmic maturation of oocytes and protect oocytes from oxidative damage in the embryonic developmental process after the fertilization $[39,40]$. Thus, the GSH content can reflect the oocyte quality. This experiment examined GSH content in oocytes of different grades by $\mathrm{BCB}$ selection. The GSH content in BCB+ oocytes was $6.39 \mathrm{pM}$, significantly higher than $0.26 \mathrm{pM}$ in $\mathrm{BCB}-$ oocytes $(P<0.01)$. This indicates that $\mathrm{BCB}+$ oocytes have better quality than $\mathrm{BCB}-$ oocytes.

In the different developmental stages of oocytes and embryos, GDF9, mater, zarl, and other maternal genes were expressed differently [27-29]. In the study on the expression of three types of maternal mRNA (Mater, Zar1, and GDF9) in sheep oocytes and early embryos, our laboratory [30] found that with oocyte maturation and embryo development, the expression gradually declines. Thus, upon the maturation of oocytes, mRNA expression of the three maternal genes in completely matured oocytes is very low. After 24 hours of maturation, the mRNA expression of the 3 maternal genes in $\mathrm{BCB}+$ oocytes was significantly lower than in the $\mathrm{BCB}-$ 
oocytes, indicating that $\mathrm{BCB}+$ oocytes have better quality than BCB- oocytes.

In conclusion, based on the comparison of in vitro culture, oocyte diameter, GSH content, maternal gene expression (GDF9, mater, zar1) between the $\mathrm{BCB}+$ and $\mathrm{BCB}-$ sheep oocytes, $\mathrm{BCB}+$ sheep oocytes were fully demonstrated to have better quality than $\mathrm{BCB}-$ sheep oocytes. Therefore, the $\mathrm{BCB}$ test is a useful method for selecting more competent immature sheep oocytes.

\section{Authors' Contribution}

L. Wang and J. Lin equally contributed in this paper.

\section{Acknowledgments}

This paper was supported by The High Technology Research and Development Program of Xinjiang Uygur Autonomous Region of China (no. 201111113 and no. 200711104).

\section{References}

[1] I. Gordon, Laboratory Production of Cattle Embryos, I. Gordon. CABI, New York, NY, USA, 2003.

[2] V. Madison, B. Avery, and T. Greve, "Selection of immature bovine oocytes for developmental potential in vitro," Animal Reproduction Science, vol. 27, no. 1, pp. 1-11, 1992.

[3] F. De Loos, T. van Beneden, T. A. M. Kruip, and P. van Maurik, "Structural aspects of bovine oocyte maturation in vitro," Molecular Reproduction and Development, vol. 31, no. 3, pp. 208-214, 1992.

[4] F. Mangia and C. J. Epstein, "Biochemical studies of growing mouse oocytes: preparation of oocytes and analysis of glucose6-phosphate dehydrogenase and lactate dehydrogenase activities," Developmental Biology, vol. 45, no. 2, pp. 211-220, 1975.

[5] E. Knobil and J. D. Neill, Eds., The Physiology of Reproduction, Raven Press, New York, NY, USA, 1988.

[6] P. Wassarman and D. Albertini, "The mammalian ovum," in The Physiology of Reproduction, E. Knobil and J. D. Neill, Eds., vol. 1, pp. 69-102, Raven Press, New York, NY, USA, 1988.

[7] S. Ericsson, M. Boice, H. Funahashi, and B. Day, "Assessment of porcine oocytes using brilliant cresyl blue," Theriogenology, vol. 39, no. 1, p. 214, 1993.

[8] J. Roca, E. Martinez, J. M. Vazquez, and X. Lucas, "Selection of immature pig oocytes for homologous in vitro penetration assays with the brilliant cresyl blue test," Reproduction, Fertility and Development, vol. 10, no. 6, pp. 479-485, 1998.

[9] S. H. El Shourbagy, E. C. Spikings, M. Freitas, and J. C. S. John, "Mitochondria directly influence fertilisation outcome in the pig," Reproduction, vol. 131, no. 2, pp. 233-245, 2006.

[10] E. Rodríguez-González, M. López-Béjar, E. Velilla, and M. T. Paramio, "Selection of prepubertal goat oocytes using the brilliant cresyl blue test," Theriogenology, vol. 57, no. 5, pp. 1397-1409, 2002.

[11] E. Rodríguez-Gonzáles, M. López-Bejar, D. Izquierdo, and M. T. Paramio, "Developmental competence of prepubertal goat oocytes selected with brilliant cresyl blue and matured with cysteamine supplementation," Reproduction Nutrition Development, vol. 43, no. 2, pp. 179-187, 2003.

[12] A. Urdaneta, A. R. Jiménez-Macedo, D. Izquierdo, and M. T. Paramio, "Supplementation with cysteamine during maturation and embryo culture on embryo development of prepubertal goat oocytes selected by the brilliant cresyl blue test," Zygote, vol. 11, no. 4, pp. 347-354, 2003.

[13] M. Pujol, M. López-Béjar, and M. T. Paramio, "Developmental competence of heifer oocytes selected using the brilliant cresyl blue (BCB) test," Theriogenology, vol. 61, no. 4, pp. 735-744, 2004.

[14] H. Alm, H. Torner, B. Löhrke, T. Viergutz, I. M. Ghoneim, and W. Kanitz, "Bovine blastocyst development rate in vitro is influenced by selection of oocytes by brillant cresyl blue staining before IVM as indicator for glucose-6-phosphate dehydrogenase activity," Theriogenology, vol. 63, no. 8, pp. 2194-2205, 2005.

[15] S. Bhojwani, H. Alm, H. Torner, W. Kanitz, and R. Poehland, "Selection of developmentally competent oocytes through brilliant cresyl blue stain enhances blastocyst development rate after bovine nuclear transfer," Theriogenology, vol. 67, no. 2, pp. 341-345, 2007.

[16] B. M. Manjunatha, P. S. P. Gupta, M. Devaraj, J. P. Ravindra, and S. Nandi, "Selection of developmentally competent buffalo oocytes by brilliant cresyl blue staining before IVM," Theriogenology, vol. 68, no. 9, pp. 1299-1304, 2007.

[17] Y. G. Wu, Y. Liu, P. Zhou et al., "Selection of oocytes for in vitro maturation by brilliant cresyl blue staining: a study using the mouse model," Cell Research, vol. 17, no. 8, pp. 722-731, 2007.

[18] B. A. Rodrigues, P. Rodriguez, A. E. F. Silva, L. F. Cavalcante, C. Feltrin, and J. L. Rodrigues, "Preliminary study in immature canine oocytes stained with brilliant cresyl blue and obtained from bitches with low and high progesterone serum profiles," Reproduction in Domestic Animals, vol. 44, no. 2, pp. 255-258, 2009.

[19] T. Otoi, K. Yamamoto, N. Koyama, S. Tachikawa, and T. Suzuki, "Bovine oocyte diameter in relation to developmental competence," Theriogenology, vol. 48, no. 5, pp. 769-774, 1997.

[20] J. Kim, J. You, S. H. Hyun, G. Lee, J. Lim, and E. Lee, "Developmental competence of morphologically poor oocytes in relation to follicular size and oocyte diameter in the pig," Molecular Reproduction and Development, vol. 77, no. 4, pp. 330-339, 2010.

[21] B. Anguita, A. R. Jimenez-Macedo, D. Izquierdo, T. Mogas, and M. T. Paramio, "Effect of oocyte diameter on meiotic competence, embryo development, p34 (cdc2) expression and MPF activity in prepubertal goat oocytes," Theriogenology, vol. 67, no. 3, pp. 526-536, 2007.

[22] F. Rausell, J. F. Pertusa, V. Gómez-Piquer et al., "Beneficial effects of dithiothreitol on relative levels of glutathione Stransferase activity and thiols in oocytes, and cell number, DNA fragmentation and allocation at the blastocyst stage in the mouse," Molecular Reproduction and Development, vol. 74, no. 7, pp. 860-869, 2007.

[23] Z. Luberda, "The role of glutathione in mammalian gametes," Reproductive Biology, vol. 5, no. 1, pp. 5-17, 2005.

[24] K. A. Zuelke, S. C. Jeffay, R. M. Zucker, and S. D. Perreault, "Glutathione (GSH) concentrations vary with the cell cycle in maturing hamster oocytes, zygotes, and pre-implantation stage embryos," Molecular Reproduction and Development, vol. 64, no. 1, pp. 106-112, 2003.

[25] N. Maedomari, K. Kikuchi, M. Ozawa et al., "Cytoplasmic glutathione regulated by cumulus cells during porcine oocyte maturation affects fertilization and embryonic development in vitro," Theriogenology, vol. 67, no. 5, pp. 983-993, 2007.

[26] E. Curnow, J. Ryan, D. Saunders, and E. Hayes, "241 Strategies to improve glutathione content of in vitro-matured bovine oocytes," Reproduction Fertility and Development, vol. 20, no. 1, p. 200, 2008. 
[27] W. X. Liao, R. K. Moore, F. Otsuka, and S. Shimasaki, "Effect of intracellular interactions on the processing and secretion of bone morphogenetic protein-15 (BMP-15) and growth and differentiation factor-9: implication of the aberrant ovarian phenotype of BMP-15 mutant sheep," The Journal of Biological Chemistry, vol. 278, no. 6, pp. 3713-3719, 2003.

[28] Z. B. Tong, L. Gold, A. De Pol et al., "Developmental expression and subcellular localization of mouse MATER, an oocyte-specific protein essential for early development," Endocrinology, vol. 145, no. 3, pp. 1427-1434, 2004.

[29] F. Paradis, S. Novak, G. K. Murdoch, M. K. Dyck, W. T. Dixon, and G. R. Foxcroft, "Temporal regulation of BMP2, BMP6, BMP15, GDF9, BMPR1A, BMPR1B, BMPR2 and TGFBR1 mRNA expression in the oocyte, granulosa and theca cells of developing preovulatory follicles in the pig," Reproduction, vol. 138, no. 1, pp. 115-129, 2009.

[30] H. Min, L. Jia-peng, H. Jun-cheng et al., "The expression of maternal-effect genes Gdf9, Zar1, Mater, and Dnmt1 mRNA in ovine oocytes and in vitro embryos," China Herbivores, no. 2, pp. 5-10, 2010.

[31] H. M. Raghu, S. Nandi, and S. M. Reddy, "Follicle size and oocyte diameter in relation to developmental competence of buffalo oocytes in vitro," Reproduction, Fertility and Development, vol. 14, no. 1-2, pp. 55-61, 2002.

[32] M. Pujol, M. Lopez-Bejar, M. J. Mertens, E. RodriguezGonzales, E. Velilla, and M. T. Paramio, "Selection of immature oocytes using the brillant cresyl blue test," Theriogenology, vol. 53, p. 466, 2000.

[33] E. Rodriguez-Gonzalez, M. Lopez-Bejar, E. Velilla, and M. T. Paramio, "Selection of prepubertal goat oocytes using the brillant cresyl blue test," Theriogenology, vol. 57, no. 5, pp. 1397-1409, 2002.

[34] M. Gracia Catalá, D. Izquierdo, S. Uzbekova et al., "Brilliant Cresyl Blue stain selects largest oocytes with highest mitochondrial activity, maturation-promoting factor activity and embryo developmental competence in prepubertal sheep," Reproduction, vol. 142, no. 4, pp. 517-527, 2011.

[35] G. J. Tiffin, D. Rieger, K. J. Betteridge, B. R. Yadav, and W. A. King, "Glucose and glutamine metabolism in pre-attachment cattle embryos in relation to sex and stage of development," Journal of Reproduction and Fertility, vol. 93, no. 1, pp. 125132, 1991.

[36] N. Crozet, M. Ahmed-Ali, and M. P. Dubos, "Developmental competence of goat oocytes from follicles of different size categories following maturation, fertilization and culture in vitro," Journal of Reproduction and Fertility, vol. 103, no. 2, pp. 293-298, 1995.

[37] P. Damiani, R. Fissore, J. Cibelli et al., "Evaluation of developmental competence, nuclear and ooplasmic maturation of calf oocytes," Molecular Reproduction and Development, vol. 45, no. 4, pp. 521-534, 1996.

[38] D. G. de Matos, B. Gasparrini, S. R. Pasqualini, and J. G. Thompson, "Effect of glutathione synthesis stimulation during in vitro maturation of ovine oocytes on embryo development and intracellular peroxide content," Theriogenology, vol. 57, no. 5, pp. 1443-1451, 2002.

[39] D. G. De Matos and C. C. Furnus, "The importance of having high glutathione (GSH) level after bovine in vitro maturation on embryo development effect of $\beta$-mercaptoethanol, cysteine and cystine," Theriogenology, vol. 53, no. 3, pp. 761-771, 2000.

[40] M. Ozawa, T. Nagai, T. Somfai et al., "Cumulus cell-enclosed oocytes acquire a capacity to synthesize GSH by FSH stimulation during in vitro maturation in pigs," Journal of Cellular Physiology, vol. 222, no. 2, pp. 294-301, 2010. 

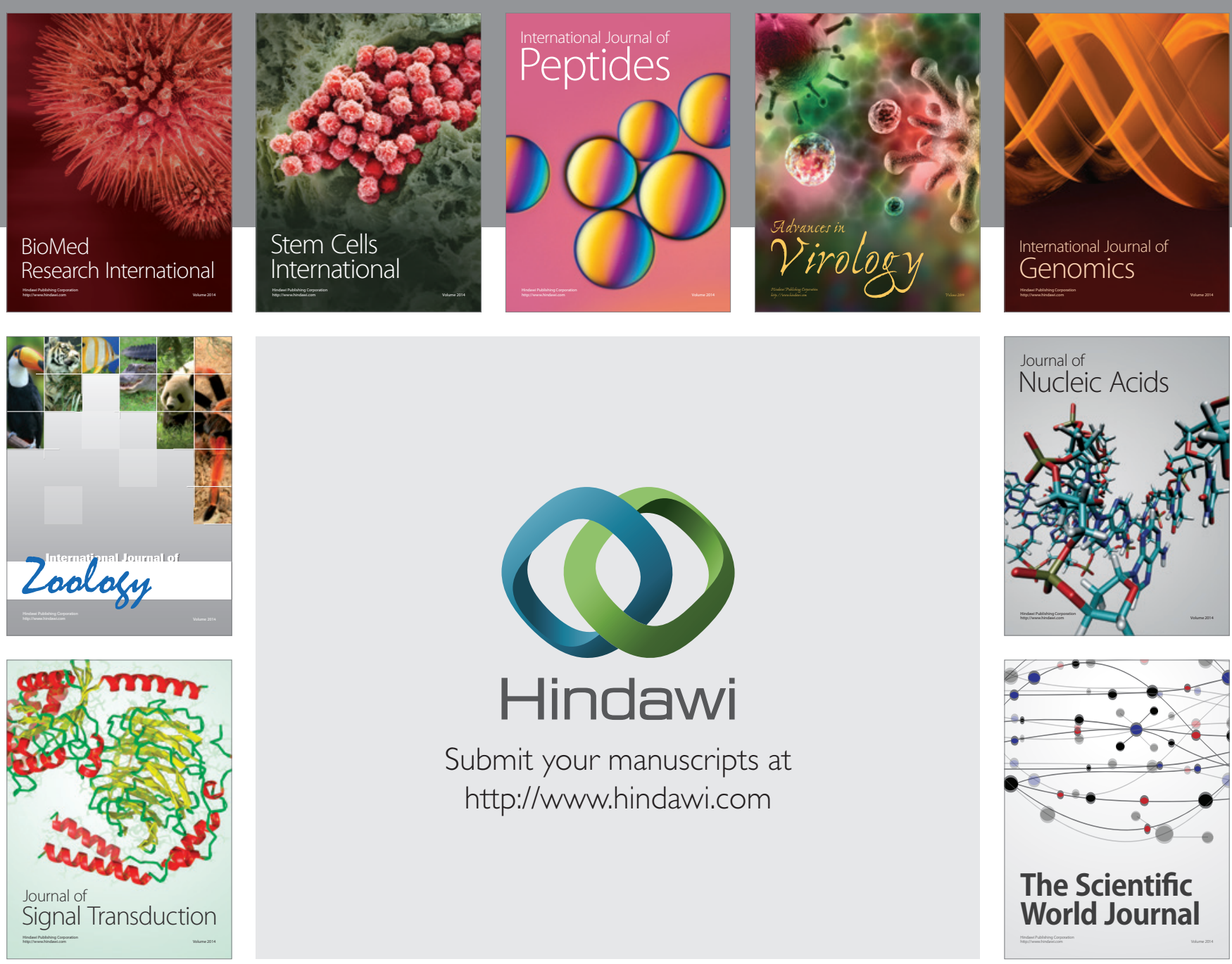

Submit your manuscripts at

http://www.hindawi.com
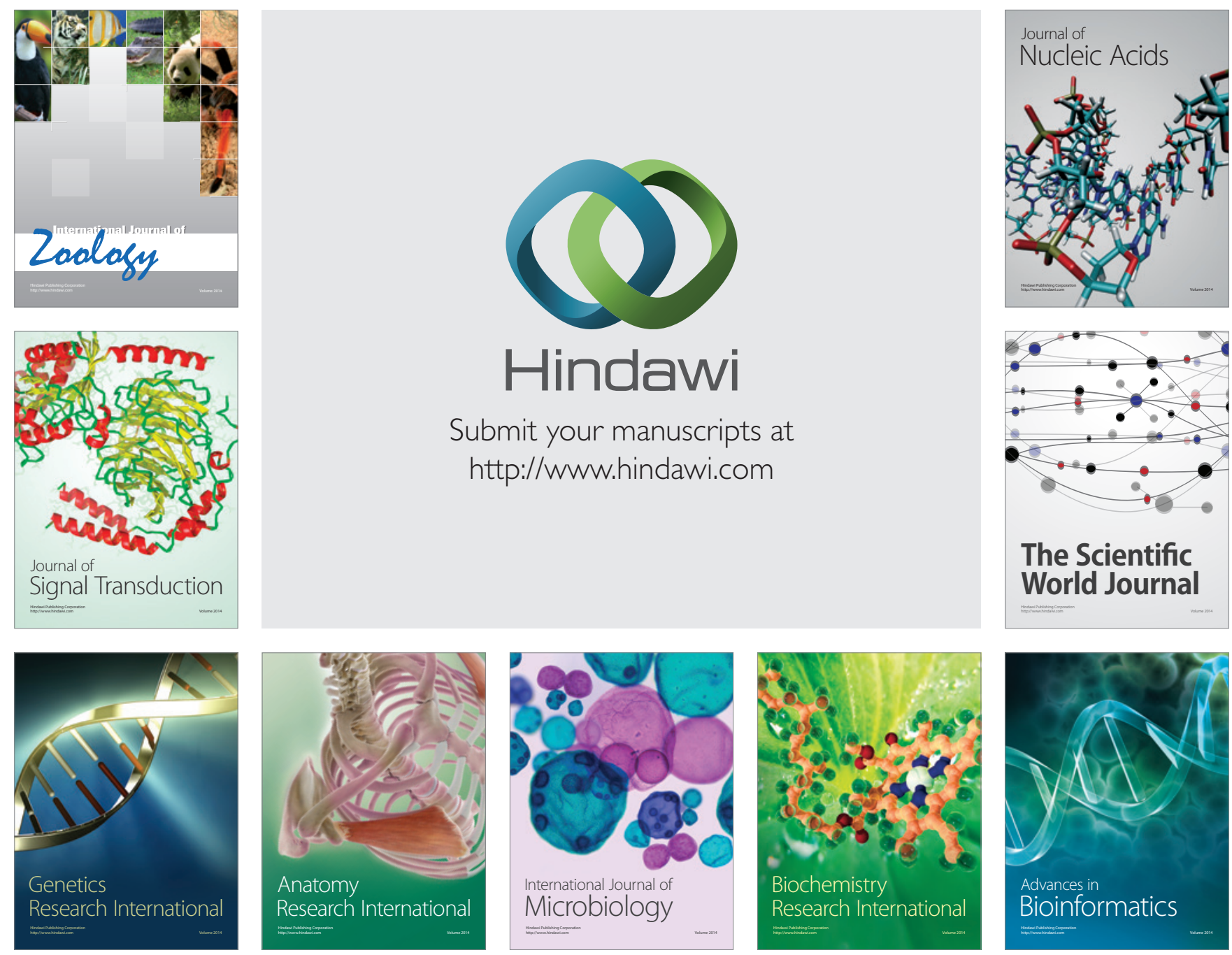

The Scientific World Journal
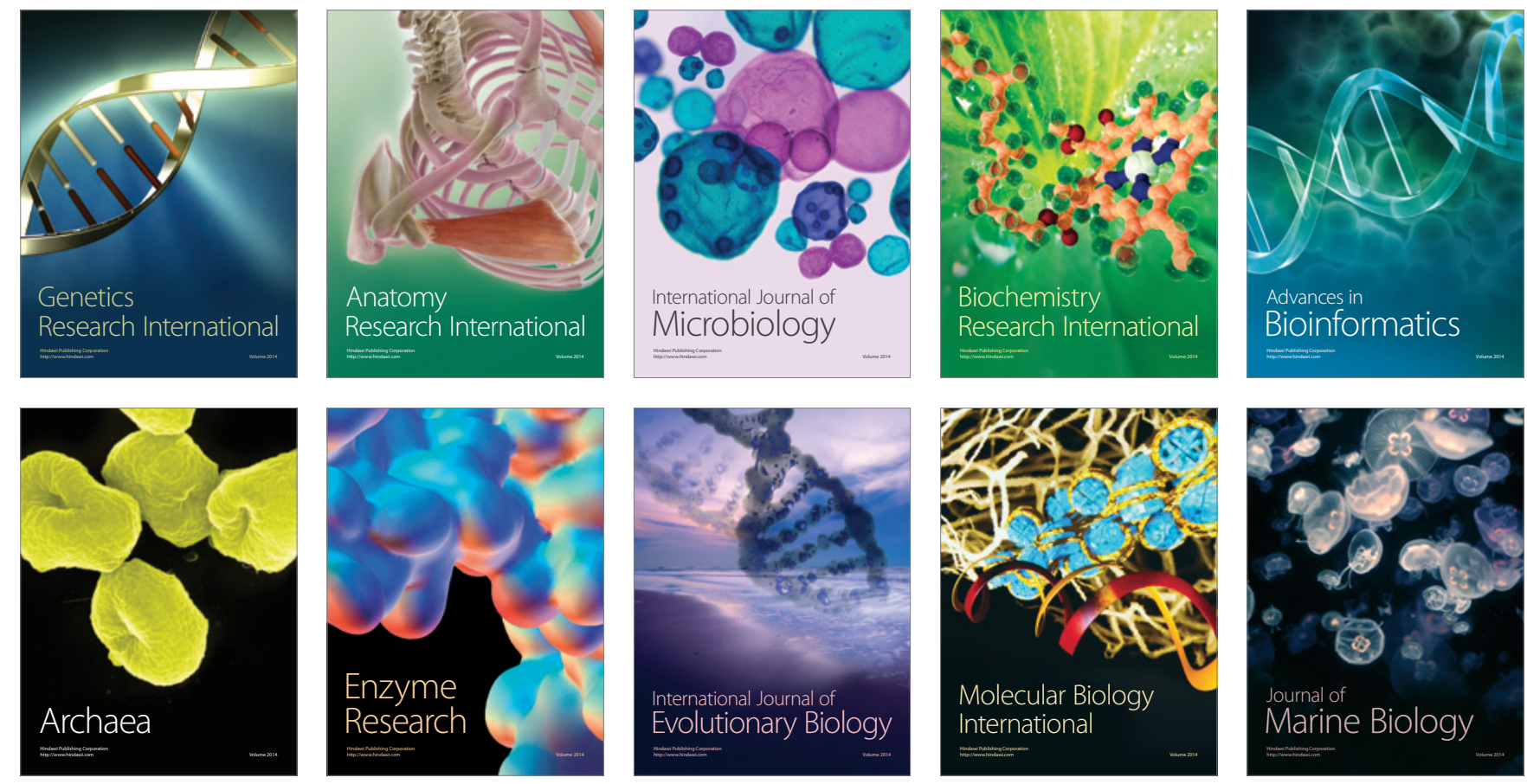